\title{
Point-to-point Transportation Analysis for Domestic Travel in Malaysia
}

Chapter · May 2015

DOI: 10.1201/b18407-48

READS

17

2 authors, including:

Fairuz Izzuddin Romli

Universiti Putra Malaysia

44 PUBLICATIONS 51 CITATIONS

SEE PROFILE 


\title{
Point-to-point transportation analysis for domestic travel in Malaysia
}

\author{
F.I. Romli \& H. Rashid \\ Department of Aerospace Engineering, Faculty of Engineering, Universiti Putra Malaysia, Serdang, \\ Selangor, Malaysia
}

\begin{abstract}
Point-to-point travel refers to the trip taken from the initial departure point to the final destination point, which can be further categorized as either direct or non-direct. Direct point-to-point travel indicates that the trip is made with a single transportation mode from beginning until the person reaches the final destination. On the other hand, the non-direct type of point-to-point travel involves several modes of transportation throughout the journey. Comparison analysis is made between the available modes of domestic transportation such as buses, trains, commercial flights and cars to determine the preference and the market potential for direct point-to-point travel means. Several evaluation criteria including time on transport, time of waiting, cost of transport, cost of other expenses, travel comfort, flexibility of departure point and privacy are used in this study. Based on the result from case studies of domestic travel in Malaysia, it shows that direct point-to-point means of transportation represented by cars generally have higher benefits in comparison to other means of transportation, especially in terms of time and travel costs. This signifies a big potential in introducing a better means of direct point-to-point transportation than current cars like the dual-mode Personal Air Vehicle (PAVE) for domestic travel in Malaysia.
\end{abstract}

\section{INTRODUCTION}

Transportation has brought interest in the discussion of feasible development due to the constant growth in personal mobility and its correlated environmental costs (Frändberg \& Vilhelmson, 2011). Today, there are several different modes of transportation that are used by the majority of people in their daily life to travel from one point to another. Their choice of transportation mode depends on few personal considerations. For example, some people are mainly concerned on how much they have to pay for the transportation regardless of the time taken to travel while others may think the opposite. It has been suggested that travel demand is typically constrained by the time budget while the choice of travel mode is frequently dictated by the traveler's financial budget (Hahn, 2006).

In general, modes of transportation can be classified as direct or non-direct point-to-point. The direct point-to-point travel, or sometimes also known as direct door-to-door travel, is defined as a direct travelling from one point to the destination point using only a single mode of transportation. This means there is no need to change transportation mode throughout the journey. For instance, domestic travel between the cities within Peninsular Malaysia using a personal car is considered as direct point-to-point since the traveler can depart with his/her car directly from any departure point and arrive at the intended destination point with the same car in ideal circumstances. There is no need to use another different mode of transportation throughout the journey. In most parts of the world, the cars and motorcycles are the only currently available modes of transport that have the capability for direct point-to-point travel, depending also on available facilities between the travel points. It is anticipated that future personal travels will emphasize more on having a doorstep-todestination journey at any time, in any weather and in as little travel time as possible (Marchman et al, 2002). This notion puts heavy emphasis on future capability of direct point-to-point travel.

In Malaysia, numbers of motor vehicles have increased over the years. From 2009 to 2010, cars have recorded the highest increment at 608,840 units whereas motorcycles are second with 501,677 units, followed by taxis (5,512 units), buses (2,568 units) and other transport vehicles like aircraft and trains with 21,510 units (Ministry of Transport Malaysia, 2010). It can be implied from the statistics that cars and motorcycles are the preferred mode of transportation for domestic travel in Malaysia. This can also be interpreted that many Malaysians prefer to have the capability for direct point-to-point travel. In support of this notion, this paper aims to further examine direct point-topoint domestic travel in Malaysia. 


\section{MODES OF DOMESTIC TRAVEL IN MALAYSIA}

In Malaysia, there are few types of domestic transportation means that include land, maritime and air transportation. The examples of land transportation include both those on road and rail such as cars, motorcycles, buses and rail vehicles like trains, Light Rail Transit (LRT) and monorail. The maritime transport is usually associated with cargo that involves import and export of goods, apart from passenger transportation, similarly for air transportation. These transportations have utility fees based on the number of trips they generate, providing a direct connection between demands for transportation facilities and costs of constructing and maintaining them (Junge \& Levinson, 2012). Other than that, walking and bicycling are also considered as transport means. They are among active transportation means that involve physical activities specifically for travel. Many travelers typically use the active transportation for shortdistance travel due to common factors such as costs and indirect improvement of their health.

All the above transportations have their own link or network within Malaysia and they can be used interchangeably at points of operational intersections. For domestic on-ground travel in Malaysia, people can use rail vehicles or buses as their mode of transportation. In short, the monorail is used for public transportation within Kuala Lumpur while the only funicular railway line is in Pulau Pinang. LRT that is used in Kuala Lumpur has two lines of railway. The first one is the Kelana Line that covers the areas between Gombak and Kelana Jaya, while the other one is the Ampang Line that covers areas between Sentul Timur and Sri Petaling. Meanwhile, KTM Intercity provides alternative choice for passengers with a variety of couch seating categories and destinations including Peninsular Malaysia. KTM Commuter connects Kuala Lumpur city areas with the surrounding suburban areas such as Tanjung Malim, Rawang, Seremban, Sungai Gadut and Pelabuhan Klang. In addition, there are more than 100 bus companies that provide transportation services in Malaysia. A famous bus company is the state-run Transnasional that provides the most extensive coverage of bus routes service in Malaysia. The other companies like Alisan Golden Coach Express, LionStar Express, Unititi Express, KKKL, Delima Express, Konsortium Express, Sri Maju Yakin BG Express and Grassland, to name a few, also provide services for domestic travel. For air transportation services, domestic flights within Peninsular Malaysia are provided by the full-service national airline carrier that is Malaysia Airlines and several low-cost airlines such as Air Asia, FireFly and Malindo Air.
For ground transportation facilities, there are built highways that connect the roads in Malaysia. In this study, the North-South Expressway (NSE) has been used as the main facility to travel within the Peninsular Malaysia. The NSE runs from Bukit Kayu Hitam in Kedah, near the Malaysia-Thailand border, all the way to Johor Bahru at the southern part of Peninsular Malaysia. This expressway links many major cities and towns in the western Peninsular Malaysia, acting as the 'backbone' connection line of the west coast of the peninsula. It provides a faster alternative to the old state routes, thus reducing the travelling time between various towns and cities. On the other hand, available airports in Malaysia consist of international airport, domestic airport and also airstrip. The airports are built and located throughout Malaysia including Peninsular Malaysia, Sabah and Sarawak. The international airport, which is for flights arriving and departing from/to other countries, has larger facility and also longer runway compared to the domestic airport. Meanwhile, small airstrips offers runway and simple facilities like fueling equipment.

\section{COMPARISON STUDY}

Comparison between the available modes of transportation for domestic travel in Malaysia is done using the Technique for Order Preference by Similarity to Ideal Solution (TOPSIS). The key idea here is that the best alternative is the one that is as close as possible to the positive ideal solution and as far as possible to the negative-ideal solution. Positive ideal is a set of best-possible values for each of the evaluation criteria whereas negative ideal represents the worst-case of each evaluation criterion. In this study, several variables are identified as important evaluation criteria: time on transport, time of waiting, cost of transport, cost of indirect travel expenses like food, drinking water and snacks, flexibility of departure point, travel comfort and privacy. These criteria are further defined in Table 1 and a typical rating scale used in the evaluation process is as presented in the following Table 2.

Two case studies are done under the assumption of the normal road traffic conditions for this research paper. This is a rather significant assumption as traffic conditions can severely affect the evaluation criteria listed in Table 1 . The first case is designed as a domestic travel from the Kuala Lumpur Convention Centre (KLCC), Kuala Lumpur to the Pekan Rabu in Alor Setar, Kedah. In the meantime, the second case considers the travel from the KLCC, Kuala Lumpur to the Johor Bahru City Square in Johor. Seven different weighting scenarios are developed to study 
Table 1. Evaluation criteria for TOPSIS.

\begin{tabular}{|c|c|}
\hline Criteria & Definition \\
\hline Time on transport & $\begin{array}{l}\text { Time taken for the overall journey, } \\
\text { from the departure point up } \\
\text { until the final destination point. }\end{array}$ \\
\hline Time of waiting & $\begin{array}{l}\text { Time spent waiting for the mode } \\
\text { of transport to start the travel- } \\
\text { ling journey. }\end{array}$ \\
\hline Cost of transport & $\begin{array}{l}\text { Total cost of travel due only to } \\
\text { the fees or the incurred travel } \\
\text { expenses such as toll fees, fuel, } \\
\text { etc. of the transport. }\end{array}$ \\
\hline $\begin{array}{l}\text { Cost of indirect } \\
\text { travel expenses }\end{array}$ & $\begin{array}{l}\text { Total cost incurred for the travel } \\
\text { excluding the cost of transport. } \\
\text { This includes foods, drinks, etc. } \\
\text { while waiting at the station. }\end{array}$ \\
\hline $\begin{array}{l}\text { Flexibility of } \\
\text { departure point }\end{array}$ & $\begin{array}{l}\text { Measure of flexibility level to start } \\
\text { the travel from any departure } \\
\text { point. }\end{array}$ \\
\hline Travel comfort & $\begin{array}{l}\text { Measure of travelling comfort } \\
\text { throughout the journey. }\end{array}$ \\
\hline Privacy & $\begin{array}{l}\text { Measure of provided privacy level } \\
\text { throughout the journey. }\end{array}$ \\
\hline
\end{tabular}

Table 2. Rating scale for TOPSIS.

Rating Explanation

1 Performance level of the evaluation criterion is estimated to be very low compared to the perceived travel preference.

Performance level of the evaluation criterion is estimated to be low compared to the perceived travel preference.

4 Performance level of the evaluation criterion is estimated to be moderately low compared to the perceived travel preference.

5 Performance level of the evaluation criterion is estimated to be on average compared to the perceived travel preference.

6 Performance level of the evaluation criterion is estimated to be moderately high compared to the perceived travel preference.

Performance level of the evaluation criterion is estimated to be high compared to the perceived travel preference.

9 Performance level of the evaluation criterion is estimated to be very high compared to the perceived travel preference.

Table 3. Evaluation scenarios for TOPSIS.

\begin{tabular}{|c|c|}
\hline Scenario & Description \\
\hline Travel time & $\begin{array}{l}\text { This scenario emphasizes on the shortest travel time taken for the journey. In this particular scenario, } \\
\text { both shortest time on transport in the travel and time of waiting for the transport to arrive are the } \\
\text { upmost importance. Hence, the weighting for time on transport and time of waiting for the } \\
\text { transport are assigned as } 0.25 \text { each while the other criteria are assigned } 0.1 \text { each. }\end{array}$ \\
\hline Cost & $\begin{array}{l}\text { This scenario emphasizes on the lowest cost for the journey. In this particular scenario, both lowest } \\
\text { cost of transport (fees) and cost of other expenses such as drinking water, meals and others dur- } \\
\text { ing waiting time are the upmost importance. Hence, the weighting for cost of transport and cost of } \\
\text { other expenses time are assigned as } 0.25 \text { each while the other criteria are assigned } 0.1 \text { each. }\end{array}$ \\
\hline $\begin{array}{l}\text { Departure } \\
\text { point } \\
\text { flexibility }\end{array}$ & $\begin{array}{l}\text { This scenario emphasizes on the flexibility of travel for the journey. In this particular scenario, the best } \\
\text { case is to be able to start the journey straightaway from the initial departure point without the need } \\
\text { to go to a fixed hub. Hence, weighting for departure point flexibility is given as } 0.25 \text { while the other } \\
\text { criteria are assigned } 0.125 \text { each. }\end{array}$ \\
\hline Comfort & $\begin{array}{l}\text { This scenario emphasizes on the comfort level throughout the travel for the journey. In this particular } \\
\text { scenario, it is based on the comfortability of the passenger while on transport, time of arrival either } \\
\text { day or night and how they feel when arrived at night. Hence the weighting for travel comfort is } \\
\text { assigned as } 0.25 \text { while the other criteria are assigned } 0.125 \text { each. }\end{array}$ \\
\hline Privacy & $\begin{array}{l}\text { This scenario emphasizes on the level of privacy provided throughout the travel for the journey. In this } \\
\text { particular scenario, factors such as seating arrangement (or group seating) and type of seating play a big } \\
\text { role. Hence, the weighting for privacy is assigned as } 0.25 \text { while the other criteria are given } 0.125 \text { each. }\end{array}$ \\
\hline Balance & $\begin{array}{l}\text { In this scenario, all evaluation criteria are taken to be of equal importance. Hence, all criteria are } \\
\text { assigned with equal weighting of } 0.1428 \text { each. }\end{array}$ \\
\hline All rounded & $\begin{array}{l}\text { In this scenario, it is taken that time on transport, cost of transport, flexibility of departure point } \\
\text { and comfort are the important criteria with assigned weighting of } 0.175 \text { each while the other are } \\
\text { assigned with } 0.1 \text { each. }\end{array}$ \\
\hline
\end{tabular}

the effects of the different travelers' preferences. This is essential to cover the diversity aspects of decision-making process in selecting available travel options and highlight the robustness of the travelling means.
For instance, if travel time is the most important selection criterion for the traveler in choosing his/ her transportation option, this condition can be reflected with a higher weighting for time on the transport and also waiting time for the transport 
in comparison to the other evaluation criteria. These different scenarios are further described in Table 3.

\section{RESULTS AND DISCUSSIONS}

In the first case study, it involves travel trip from the Kuala Lumpur Convention Centre (KLCC) to Pekan Rabu in Alor Setar, Kedah. For the purpose of dictating the ticket fare and timetable of the available public transportation services, it is taken on Wednesday, 23rd April 2014 and the departure time is assumed to be at $10.20 \mathrm{a} . \mathrm{m}$. Based on the evaluation criteria listed in Table 1 and using the rating scale as outlined in Table 2, the assessment is done for this travel trip for different main transportation modes for all seven different evaluation scenarios (and importance weightings) in Table 3. For each scenario, the results of closeness rating in TOPSIS for the different transportation modes are presented in Table 4.

A closer look at the results can be made by looking at the web chart presented in Figure 1. From the figure, it is observed that car consistently obtains a high closeness rating in most of the different evaluation scenarios considered in the TOPSIS evaluation. It places second on only two scenarios, which are the travel time and cost, while appears on top in all other scenarios.

Table 4. Closeness rating for case study 1 .

\begin{tabular}{lllll}
\hline Scenario & Bus & Train & Car & Airplane \\
\hline Travel time & 0.6620 & 0.1756 & 0.6621 & $\mathbf{0 . 6 8 7 2}$ \\
Cost & $\mathbf{0 . 7 7 2 8}$ & 0.5131 & 0.7343 & 0.4530 \\
$\begin{array}{l}\text { Departure point } \\
\quad 0.5751\end{array}$ & 0.3630 & $\mathbf{0 . 8 1 3 0}$ & 0.4942 \\
$\quad$ flexibility & & & & \\
Comfort & 0.5788 & 0.3532 & $\mathbf{0 . 8 1 2 1}$ & 0.5272 \\
Privacy & 0.5706 & 0.3535 & $\mathbf{0 . 8 2 0 9}$ & 0.4728 \\
Balance & 0.6367 & 0.3701 & $\mathbf{0 . 8 0 1 2}$ & 0.5292 \\
All rounded & 0.6150 & 0.4390 & $\mathbf{0 . 7 7 0 6}$ & 0.4872
\end{tabular}

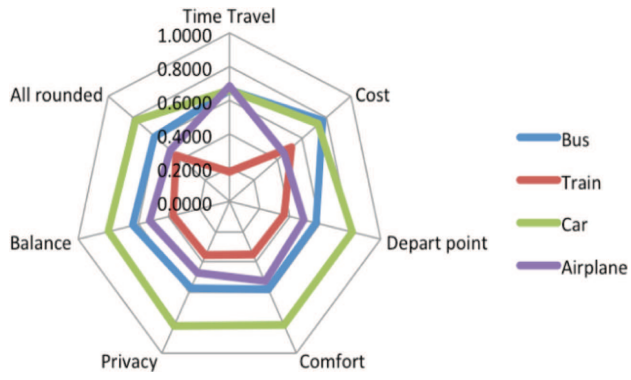

Figure 1. TOPSIS results for case study 1.
In the time travel scenario, an aircraft surely has the shortest travel time over the majority of the distance involved in the trip. Nonetheless, as reflected by a small score difference between taking flight and driving a car for the trip, the latter has indeed countered the aircraft's advantage with the benefits of not having to wait for the transport. The travel trip can be started straightaway by car but when an aircraft is chosen, the traveler may have to wait at the airport for the scheduled departure time, thus delaying the arrival time at the intended final destination.

On the other hand, in terms of cost, it appears that taking the bus for the trip will incur the least amount of travel costs. In addition to fuel, traveling by car also involves paying the highway's toll fares. Furthermore, the total costs of traveling by bus are being shared with other passengers, as already distributed in the bus ticket price. Nonetheless, the score difference is comparatively small between car and bus for the particular evaluation scenario, indicating that the total costs of using these two transportation means may not differ that much.

Overall, based on the TOPSIS results of first case study, it can be said that direct point-to-point travel as represented by car is the most preferable and robust for the different evaluation scenarios compared to the other considered means of transportation.

Similar evaluation process is done for the second case study, which is a travel trip from Kuala Lumpur Convention Centre (KLCC), Kuala Lumpur to Johor Bahru City Square in Johor. To maintain an appropriate comparison basis with the first case study, the ticket fare and timetable of available public transportation services are determined using the same travel date and time, which is on Wednesday, 23rd April 2014 and with the departure time assumed to be at 10.20 a.m. For each of the evaluation scenarios in this second case study, results of the closeness rating in TOPSIS for different transportation modes considered are presented in Table 5 and its associated web chart is depicted in Figure 2.

Table 5. Closeness rating for case study 2.

\begin{tabular}{lllll}
\hline Scenario & Bus & Train & Car & Airplane \\
\hline Travel time & 0.4260 & 0.3412 & $\mathbf{0 . 8 4 2 3}$ & 0.4456 \\
Cost & 0.6602 & 0.6588 & $\mathbf{0 . 7 6 8 2}$ & 0.2379 \\
$\begin{array}{l}\text { Departure point } \\
\quad 0.4509\end{array}$ & 0.4662 & $\mathbf{0 . 8 3 4 0}$ & 0.3186 \\
$\quad$ Comfibility & & & & \\
Privacy & 0.4540 & 0.4496 & $\mathbf{0 . 8 3 3 0}$ & 0.3559 \\
Balance & 0.4497 & 0.4461 & $\mathbf{0 . 5 5 0 3}$ & 0.3042 \\
All rounded & 0.5006 & 0.4870 & $\mathbf{0 . 8 1 9 0}$ & 0.3414 \\
& 0.5430 & 0.5252 & $\mathbf{0 . 7 9 2 1}$ & 0.3711 \\
\hline
\end{tabular}




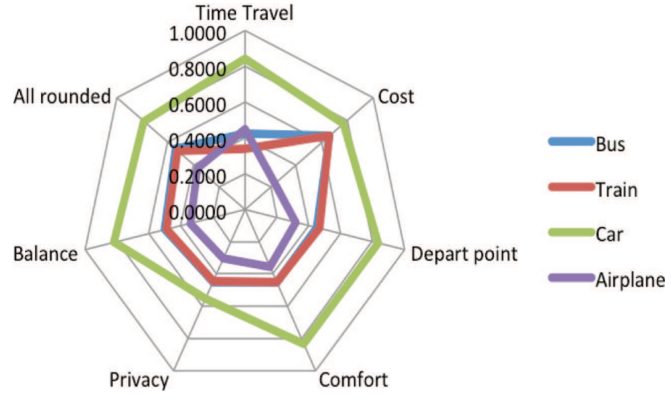

Figure 2. TOPSIS results for case study 2.

From Figure 2, car clearly is the preferred transportation means as it comes on top for all of the assessment scenarios. It should be noted that, while the cost of travel for car is not the lowest, it still beat the other transportation means due to a competitive travelling time. This highlights its high robustness in terms of satisfying the many different aspects of travelling preferences. Another thing to note from results of this second case study in comparison to the first case study is the improvement of score difference between train and bus. The main reason for this is the close availability of the scheduled public train service from KLCC to Johor Bahru with intended departure time. This reduces the waiting time and the overall travel time compared to bus, even though the latter takes much less on-the-road time to travel the distance to the destination. One of the things that is highlighted by this occurrence is the high dependency and influence of departure time for use of public transport. It is not as flexible as using private transportation means since the traveler has to follow the scheduled travel time. Overall, it can be concluded that car still emerge as the best solution for pointto-point travel from KLCC, Kuala Lumpur to Johor Bahru City Square, Johor.

\subsection{Personal Air Vehicle (PAVE)}

Based on the previous results, the preference of cars as the mode of domestic transportation means can be extended to the preference for having the capability of direct point-to-point travel. However, the high use of cars in Malaysia has also led to problems of traffic congestion. For example, in Klang Valley area alone where $21 \%$ of the nation's population or about 4.8 million people live, about $84 \%$ of them are car owners (Ariffin \& Zahari, 2013). As the result, problems of traffic congestion become more severe and this situation leads to wasted travelling time and costs, increased fuel consumption, air and noise pollution, and also elevated accident and fatality rates (Kasipillai \&
Chan, 2008). Note that previous comparison case studies are conducted under the assumption of a normal traffic conditions. If problems of the ground traffic congestion are factored in, they may outweigh some of the prescribed benefits of travelling in cars. Because the need and preference of a direct pint-to-point travel cannot be simply ignored, there is a need for new alternative mean of transportation that can improve the capability of the current cars.

It has been suggested that application of PAVE in Malaysia could provide a sound solution and also offer economic and social benefits by reducing wasted time and cost from getting stuck in traffic congestion (Romli \& Yaakob, 2014a). A dual-mode PAVE, also sometimes simply known as a flying car, technically combines performance elements of both ground and air transportation. The concept of such transportation means is not exactly new as it has already been envisioned a few decades ago in many futuristic, science-fiction movies, cartoons and books. Several design concepts for PAVE have already been researched in the United States and also European countries. For instance, a four-year myCopter project (from 2011 to 2014) has been funded by European Union to study the feasibility of having personal flying vehicles with the concept of city-wide skyway (Czyzewski, 2011). The PAVE concept considered in myCopter project is as shown in Figure 3.

To highlight the potential of PAVE for domestic travel use, the performance comparison between car and PAVE is necessary. As published in (Romli \& Yaakob, 2014b), results of cost and travel time comparison are reproduced in Table 6 for travelling case that is almost similar to the one used in the first case study, which is from the Universiti Putra Malaysia (UPM) Campus, Selangor to Pekan Rabu, Kedah.

It could be seen that the expected performance of PAVE in both travel time and cost aspects exceeds

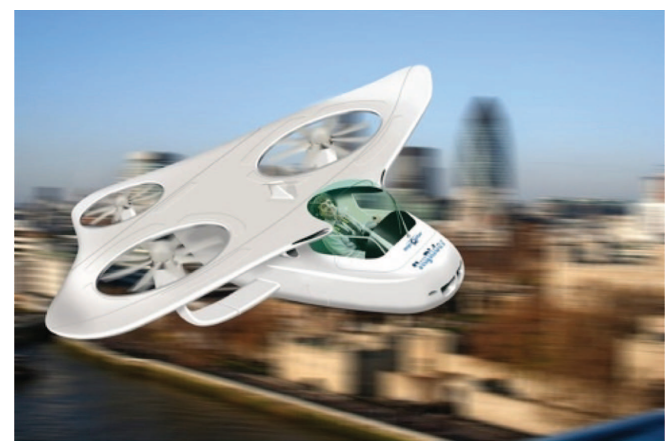

Figure 3. PAVE concept in EU myCopter Project (Czyzewski, 2011). 
Table 6. Comparison of car and PAVE for travel trip from UPM Campus, Selangor to Pekan Rabu, Kedah.

\begin{tabular}{lll}
\hline Parameter & Car & PAVE \\
\hline Travel time & 4 hours 43 minutes & 3 hours 8 minutes \\
Total cost & $\$ 50.00$ & $\$ 30.46$ \\
\hline
\end{tabular}

the capability of the current car. Hence, this raises a big potential for PAVE as an alternative transportation to cars for future direct point-to-point travel. It should be noted that the comparison was made in that study using published technical specifications and performance characteristics of Transition PAVE design as published by its manufacturer.

\section{CONCLUSION}

The purpose of this research is mainly to examine the direct point-to-point domestic travel capability in Malaysia. From the results of TOPSIS assessment for two sample case studies, it can be concluded that under normal traffic conditions the ideal result is to travel by car. This is mainly due to its flexibility and less time taken to travel, even though the overall cost of using a car is usually higher compared to the bus and train. With the limitation of the current cars, especially due to the rising problems of traffic congestion on the road, there is a need for a new alternative mean of direct point-to-point transport. Based on an example comparison between the performance of a car and a PAVE for the same case of a travel trip, it shows that PAVE seems to have a big potential edge to become better direct point-to-point mean of transport in the future.

\section{ACKNOWLEDGEMENT}

The authors acknowledge financial support for this project from Ministry of Education, Malaysia under the Fundamental Research Grant Scheme (FRGS)—FRGS/1/2012/TK09/UPM/02/1.

\section{REFERENCES}

Ariffin, R.N.R. \& Zahari, R.K. 2013. The Challenges of Implementing Urban Transport Policy in the Klang Valley, Malaysia. Procedia Environmental Sciences. 17: 469-477.

Czyzewski, A. 2011. Personal Flying Vehicles Project Aims to End Road Congestion. in The Engineer. http://www.theengi neer.co.uk [Accessed: June 2014].

Frändberg, L. \& Vilhelmson, B. 2011. More or less travel: personal mobility trends in the Swedish population focusing gender and cohort. J. Transp. Geogr. 19(6): 1235-1244.

Hahn, A. S. 2006. Next Generation NASA GA Advanced Concept. in SAE General Aviation Technology Conference and Exhibition, Wichita, USA.

Junge, J.R. \& Levinson, D. 2012. Financing transportation with land value taxes: Effects on development intensity. Journal of Transport and Land Use. 5(1): 49-63.

Kasipillai, J. \& Chan, P. 2008. Travel Demand Management: Lessons for Malaysia. Journal of Public Transportation. 11: 41-56.

Marchman, J.F., Interatep, N., Skelton, E., Mason, W.H. 2002. An Investigation of CTOL Dual-Mode PAVE Concepts. in Technical Report to NASA Langley Research Center, January 2002.

Ministry of Transport Malaysia. 2010. Statistik Pengangkutan Malaysia.

Romli, F.I. \& Yaakob, M.S. 2014a. Personal Air Vehicle (PAVE) Application in Malaysia. in International Conference on Advanced Logistics and Transport (ICALT) 2014. 59-64, 1-3 May 2014, Yassmine Hammamet: Tunisia.

Romli, F.I. \& Yaakob, M.S. 2014b. Travel Time and Cost Analysis of PAVE Application in Malaysia. Applied Mechanics and Materials. 629: 246-251. 